\title{
Microtext in the Management of Book Collections: A Symposium
}

The following two PaPERs, prepared by anonymous writers, were presented at the Con1 ference of Eastern College Librarians, Columbia University, November 29, 1952. Notes on the discussions which followed each paper are also included.

\section{Microreproduction vs. the Regional Warehousing of Research Materials}

$\mathrm{I}^{\mathrm{r}}$ HAS BEEN FREQUENTLY pointed out that all of the various forms of microtext either eliminate entirely, or greatly reduce, at least three out of the four main costs which libraries incur in providing, for the use of scholars, their less-used research materials.

But, although microtext does save something on all of these three costs-namely purchase cost, binding cost, and storage costlibrarians have, so far, in considering their purchase of it, paid very little attention to anything except their saving in the first cost out of the three. Fremont Rider in his The Scholar and the Future of the Research Library prophesied that this viewpoint on microtext saving would continue to exist for some time to come, and that it would continue to exist despite two overwhelmingly important facts: first, that when one considers research materials as a whole, the cost of storage is far greater than the cost of purchase, and second, that microtext affects a saving in this storage cost which in some cases comes gratifyingly close to $99 \%$.

A more recently published book by Rider, Compact Book Storage, went in to still more detail regarding this present lack of library interest in storage costs. It pointed out that the reason why so many librarians of research institutions are as yet relatively unaware of the staggeringly high cost of their book storage is that, in the extremely misleading forms of accounting which libraries are now following, book storage costs are almost entirely concealed costs. Most of them are factors of building cost, and library building costs are not presented afresh each year in recurring annual budgets, but were long ago buried in capital investments of which conventional library budgetary accounting has not taken notice.
But still further to mislead both the librarians and the administrators of research institutions even those book storage costs which are current operating outlays also fail to appear in our library budgets. In setting up these budgets it is assumed that the cost of operating the building that houses the library has nothing whatever to do with the cost of operating the library. But, unless we know the interest, depreciation, and obsolescence upon our library building's stacks; unless we know what we are paying for the lighting and heat, the janitorial and elevator service, and the insurance on those stacks, we can have no idea of what it costs us to store our books. These items are all inescapable parts, and very large parts, of that cost. As a matter of fact the true cost of every one of a library's operations can today be arrived at only after a lengthy and difficult analysis of a great many other budgetary items which our conventional accounting now deems of little concern to the library.

In recent years, however, two important developments have forced the librarians of all research libraries, and also their executives and trustees, to become increasingly aware that all is not well on the book storage front. One of these two developments was the analytical material which appeared in the often quoted preliminary chapters of $T$ he Scholar, material which revealed for the first time that the rates of growth of all research libraries are of a geometrical rather than an arithmetical order. The other development has been the war and post-war inflations in the costs of building, which have mounted up at rates which have been equally disconcerting.

Of all the various "solutions" that have been advanced to exercise the "curse of in- 
evitable growth" one of the most appealing has been what is known generally as "warehouse" or "regional library" storage. If we were to differentiate between these two phrases we would define "warehouse storage" as the segregation of a portion of some one library's less used books in a more cheaply constructed building situated in a more remote, and so a cheaper, location, and "regional library storage" as a cooperative effort by a number of libraries to effect the same result.

A "regional library" may, however, take one or the other of two quite different forms. It may be a cooperative "warehouse storage" center-i.e. a stack building cheaply built in a cheap location in which each library stores its own respective holdings intact. This is the type of cooperative storage exemplified by the New England Deposit Library. Or it may be a brand new, cooperatively set up and fully organized central library, in which each library's contributions are pooled into an integrated corpus, in which the identity of the constituent holdings is lost. This is the direction of growth being envisaged by the new Midwest Inter-Library Center at Chicago. The warehouse storage form of regional library' has the advantage of eliminating the cost of checking, weeding out, re-cataloging, and recall-number-marking. It has the disadvantage of retaining the staggering costs of an enormous amount of duplication in the material being stored.

The advocates of regional libraries are forced to admit, however, that both of these regional library forms, like such other panaceas for growth as "weeding out" and "division of subject fields," are in reality "confessions of avoidance." In other words-so far as the constituent libraries are concernedwhat all of these so-called "solutions" do is to solve the library growth problem by ceasing to grow, i.e. by ceasing to have available in their own libraries the books that their patrons may want. "Weeding out" takes books away from the scholar completely; but the regional library and the storage warehouse library also take away his materials, perhaps not quite as completely but still to a place more or less distant.

The trouble with any sort of "taking away" is that research workers want their libraries to be not only as complete as possible; they want them also to give them as prompt service as possible. So recourse to a distant regional library does not satisfy them. They want their materials, not a thousand miles away, or even a hundred miles away, but immediately at hand. On the other hand, if you will only give them the text of what they want, and will give it to them without delay, they are generally willing to compromise to some degree on almost every other aspect of library service.

We now come to the thesis of this morning's discussions, viz. that any librarian who makes his decision to buy a microtext solely on the basis of its saving in purchase cost alone is profoundly under-rating the possibilities for economy which microtext presents. But this under-rating is exactly what at present great many librarians are doing. It is true that they are aware that they save something on storage cost when they buy a microtext; but they look upon this storage saving as merely a byproduct of saving on purchase cost. To buy microtext in order to save storage cost as an end in itself, this is an idea that as yet hasn't really taken hold of the library profession. Or perhaps it would be more correct to say that it has begun to take hold so far as newspapers are concerned, but not as yet for books and periodicals. Yet it is vitally important for all librarians to realize-and to realize to the point of taking definite, immediate remedial action-that microtext effects far greater savings in storage cost than it effects in purchase cost, great as its savings in purchase cost usually are.

This categorical assertion can be made: when all library costs are taken into consideration, a microtext copy of a given book will always (or almost always) be cheaper than any book form text of the same book, no matter what that book text costs, no matter how it is cataloged and bound, no matter how or where it is stored. Furthermore this statement will still hold true, in almost all cases, even if the library already possesses the book in book form and so has to pay out nothing whatever to acquire it, or bind it, or catalog it. In other words, book storage cost alone is so extremely large a proportion of all book costs that, in the vast majority of cases, it alone outweighs all microtext costs.

But what this statement just made really says is this: that every research library would actually save money if it absolutely threw away almost all of the volumes now lying on its shelves-volumes which it has 
already bought, bound and cataloged, and would save money even if it had to pay out cold cash to acquire microtextual copies of them to replace them! This is the startling fact which most librarians are not yet really aware of.

Now for figures to back up this statement. All the cost figures here cited will be reduced to the same unit, which will be one average size book. An "average" size book will be here defined as an octavo one inch thick, i.e. a book of a size running about twenty-five volumes to a standard stack shelf (allowing, as usual a small portion of empty shelf for future growth). This average size book will be about five hundred pages long.

All cost accounting studies confirm the conclusion that to store a book today, in a conventional standard book stack, costs approximately sixteen cents per-year-per-volume. When, eighteen years ago, the results of the first cost analysis of book storage ever to be made were published, it was shown that, in the typical university library therein analyzed, it was costing it eight and one-half cents peryear-per-volume to store its books. The $88 \%$ rise which has occurred since, from the eight and one-half cents of 1934 to the sixteen cents of today, has been solely an inflationary one, there having been no change in the makeup of the constituent factors.

To be able to compare these per-annum book storage costs with microtext costs it is necessary to translate them into their capitalized form. Sixteen cents a year, at $5 \%$, is the interest on $\$ 3.20$. In other words, to store an average size library book requires, today, directly or indirectly, a $\$ 3.20$ investment in book stack and book stack maintenance endowment. It is true that we may, if we choose, reduce this $\$ 3.20$ investment materially by substituting for conventional stack storage some form of so-called "compact storage." And it is also true that we may house our books in some sort of a "warehouse" type of storage, meaning one located on cheaper land and in stacks which are non-fireproof, or are crowded, or are only partially lighted, or are under-heated, or are in some other respects sub-standard. If we made our warehouse storage "sub-standard" in everyone of these respects, and if also we use "compact storage" in it, we might cut our book storage investment cost down from $\$ 3.20$ a volume to perhaps $\$ 1.40$ a volume. To this last figure we would have to add certain costs that we would incur in the process of putting our unit volume into this combination of "compact" and "warehouse" storage. This transfer cost can be taken as somewhere in the neighborhood of thirty cents per average volume. We have then a range in book storage investment costs running down from conventional standard stack storage at $\$ 3.20$ a volume to compact warehouse stack storage at $\$ 1.70$ a volume.

Now let us analyze microtext costs on the same unit basis. The purchase cost of a microtext depends very largely on the size of the edition printed of it. In a ten copy edition our unit book might cost, in the case of the most expensive sort of microtext, as much as $\$ 1.30$ a copy. On the other hand, in a two hundred copy edition the cost could $\mathrm{drop}$, in the case of the least expensive sort of microtext, to as little as 60 cents a copy. The average of these two costs is 85 cents a copy. To this average we have to add another 15 cents to cover the average cost, per volume, of catalog checking, and another 30 cents as the average capitalized cost, per volume, of microtext storage. This gives a total average cost, for our unit volume in microtext form of $\$ 1.30$.

The two totals of cost thus arrived at confirm the assertion originally made, namely that the total of all costs in the case of microtext, averages less than storage cost alone as in the case of the equivalent book. It will be noted furthermore that microtext cost is so low that even at its most expensive point it is very little more expensive than book storage is at its cheapest point.

Our analysis so far has been of costs in the abstract. Let us work out, for some one specific title, taken as a sample, the comparative costs of conventional "book" storage and the costs of what we might now call "microtext substitution storage." For this sample suppose we take a United States government document set, the hundred and twenty-eight volumes of what is known as the "Official Records of the War of the Rebellion." This is a title little used in most American libraries, yet it is one that is absolutely indispensable to any scholar who is doing work in the military history of the American Civil War. It is a thick volume set, and on the shelves it occupies thirty-five linear feet of shelf space.

Every one of the largest fifty research li- 
braries in the United States is probably at present holding this set on its shelves. To carry it there is costing each one of these fifty libraries an annual storage cost (at I6 cents per "average volume") amounting to approximately $\$ 40$. An annual cost of $\$ 40$ a year, capitalized at $5 \%$, means a capital storage investment of $\$ 800$ for each library. In other words, these fifty American libraries have, between them, frozen no less than $\$ 40,000$ of their capital funds merely to keep in storage on their shelves this one little-used set.

Now let us suppose that these fifty libraries said: "Let's get a microtext of this set and throw away our book form volumes of it." This means that the complete text of it would still remain, immediately at hand for scholars, in every one of these fifty libraries; but that the capitalized cost to each library of holding it-including the full purchase cost of it in microtext form-would be cut from approximately $\$ 800$ to approximately $\$ 230$.

But now let us consider another, and very important, factor. In our comparison up to this point we have in the choice of our variables always selected, not that variable which favored microtext, but that one which was most unfavorable to it.

Let us now assume a change in just one variable. Let us assume that, when we dispose of the book form book for which we substitute a microtext copy, we receive some "salvage" return on it. To be specific again, let us take as our example, not a set like the "Rebellion Records," which is so common that it would have little or no salvage value when we discarded it, but that instead, we take some set which, in its book form, does have some realizable re-sale value. Suppose, for example, that we buy a microtext set of a periodical which, bound and in good condition, has a re-sale, second-hand, value of $\$ 2.00$ a volume. (And $\$ 2.00$ a volume-i.e., a figure less than binding cost alone-is obviously not an extravagantly high salvage value to assume. Many periodical sets are worth $\$ 5.00$ and $\$ 10.00$ a volume.)

Nevertheless, when we make just this reasonable change in just one variable, something little less than astonishing happens to our comparative cost picture. For we discover that, if we can secure even as little as $\$ 2.00$ a volume of salvage return on our discarded set in its book form, we have salvaged enough out of it: (a) to pay the entire purchase cost of the microtext set which we are substituting for the book form set; (b) enough to set up a capital fund sufficient to finance the building of the space required to house this microtext set and to cover the maintenance of this space in perpetuity; and (c) enough to return to us, besides, an actual cash profit on the substitution.

If there was ever a case in library technology of having one's cake and eating it too this substitution of microtext books for salvageable book-form books would seem to be it!

Does this mean that a book should be thrown away before there is any assurance that a microtext copy can be secured to replace it? Does it mean that every microtext substitution can be made at a profit? Does it mean that every library should buy every microtext set that is offered to it, regardless of whether it already possesses the set in book form or not? The answer to these three questions is no. But what this analysis does say is this: that the primary criterion of purchase, in the case of every microtext, should be the amount of use which will be given the title involved. Few ordinary telephone users would want to substitute a microtext telephone book for its current book-form equivalent. But no library desiring to keep a file of discarded telephone books should want to keep them in book form if microtext copies of them are available. And this is the decision that ought to be made in the case of all research materials. We are all well aware that much used titles form a very small proportion indeed of the materials housed in most research libraries. And we should be aware that, for all little-used titles, microtext presents an adequate-and a very much cheaper-substitute.

And, it might be added, a cheaper one even when the cost of reading machines is taken into consideration. For reading machines for both microfilm and micropaper are already relatively cheap, and will get steadily cheaper as the demand for them grows and renders the mass production of them possible. They are already small and usable in ordinary daylight, so that they have now become a part of regular reading room desk or table facilities rather than special apparatus requiring separate accommodations. Furthermore it must be remembered that reading machines are a capital expense, meaning that, once a library is fully equipped with them, their continuing 
annual expense is a relatively small item.

One argument that has been advanced against "microtext substitution" as a basic policy is that it is at present impossible to microduplicate some materials that are under copyright. This is true. All reputable microtext publishers are careful to protect such holders of copyright even though there is no reason why microtext re-publication should cause an original book publisher any loss. If book and periodical publishers were made familiar with the seriousness of the research librarian's storage problem, and if the full weight of the library profession were thrown behind microtext re-publication as a substitute for book storage, objections of copyright owners to the microtextual reprinting of at least all out of print materials would quickly disappear. The vast majority of warehouse storage materials are, however, out of copyright. New, live, saleable books simply do not go into warehouse storage.

So far we have been summarizing the arguments either for the substitution of a microtext copy for a book-form copy in the case of a single library, or for the substitution of microtext copies in a large number of libraries as against a non-integrated regional warehouse storage of all of the book copies of the same libraries. But a third situation is possible: what of a microtext in all of these libraries as compared with one book-form copy stored in an integrated regional library serving all of them?

From the standpoint of availability, or "stand by," cost alone the argument here is no longer in favor of microtext, for the cost of providing and storing one book-form text will certainly be less than the cost of providing and storing 50 microtexts in 50 libraries, no matter how cheap a form of microtext we may choose to use. On the other hand, when we come to regional library service, new operating costs crop up other than those of providing and storing, costs which with a local library we have not had to take into account. One of the most important of these is the expense of the long distance lending of items; and this expense is important not only because it is large per loan but also because it has to be repeated without diminishment every time a loan is made.

It has always been axiomatic that interlibrary loans are expensive. As a matter of fact, they have always been so expensive that every reported cost accounting of them shows a higher average cost per-volume on a single loan than the entire cost to a local library of buying and storing under its own roof a microtext copy of the same item. We may grant that in the past interlibrary loan costs have been altogether too high. We may grant that they can and should be reduced by a proper regional library machinery.

But it is also obvious that, even if we commit ourselves ultimately wholly to the regional library concept we shall need-to give national coverage-more than one regional library, in fact we will need a number of them. And, once we go back to multiple copies of a text, the cost argument in favor of microtext again strengthens in its validity. Furthermore it is obvious that, if we substitute for a book any sort of flat microtext of it we are going to reduce our interlibrary lending cost a very great deal in packing and shipping.

Finally, however, we come back to our basic thesis: that, when we are considering regional warehouse storage versus microtext substitution storage, the cost argument, enormously important though it is, is not the whole argument, or even the main argument. The service afforded to one's library patrons by a text stored in one's own library is so definitely better a service than that afforded by a text stored in some geographically remote regional library that this betterment in service outweighs even the cost argument in importance.

\section{Discussion}

James T. Babb (Yale): He observed that librarians will put off substitution of microtext until (I) the public is educated to it, (2) the space problem is more acute, (3) until cost accounting is compulsory for libraries. He said that Yale will subscribe to the $\$ 600$ microprint set of U. S. documents recently offered. He hopes that a cooperative venture will replace document sets now on shelves with microtext.

The only storage program he favors is integrated storage, with loss of title and no accessions program. Yale is microfilming its newspapers and disposing of the originals.

He felt the need for the physical book to exist somewhere in the Northeast, but 
thought that need would decrease. He said that the microtext program should be developed. He put little stock in salvage value and thought costs of reading machines should have been brought out.

$M$ icrotext is adequate only if the book has no bibliographical value. The anonymous writer of the paper appears to be in a hurry. If his ideas are completely followed, there would be trouble. But librarians must hurry up, or their trustees will.

Miles O. Price (Columbia): He said that he has long been a microtext enthusiast but he believes the microtext program cannot succeed until (a) material is available in that form and (b) available at a price which can be paid. He noted that discarding books costs money. To make prices really low, participation on a scale wider than just research libraries is necessary. Discarded material will have low salvage value because of the number of libraries which will be discarding.

Ralph Esterquest (Midwest Inter-Library Center): He was pleased that the paper called attention to the cost factors in supplying heat, light, and the amortization of storage. $\mathrm{He}$ objected to the implication that the microtext copy was always cheaper. Midwest Inter-Library Center has a capacity of 3 million volumes; the land value is $\$ 80,000$; the building-well-lighted, fire-proofed, air conditioned, humidity-controlled, well-furnished and landscaped-cost $\$ 850,000$, or a total cost of $\$ 930,000$.

To move 3 million volumes from cooperating libraries, with adequate controls, will cost $\$ 120,000$. Thus, the total cost is $\$ 1,050$,ooo. Converting these volumes to microfilm would cost \$15,000,000. Microcard costs would be higher. He referred to his November I, I 952 Library Journal article written around the Bulletin of the National Association of Wool Manufacturers. The cost to store the set in Chicago was given as $\$ 23.90$; to microcard it the cost was $\$ 793.90$.

Keyes D. Metcalf (Harvard): He believes microfilm has almost solved the newspaper storage problem. A few years ago, newspapers took $10 \%$ of Harvard's shelf space. $\mathrm{He}$ considers the filming of early English books an important project. Microfilm is being used for interlibrary loan.

The Official Records of the War of Rebellion can be stored in the New England De- posit Library for $\$ 6.00$ a year (actual cost \$3.6o), including heat, light and service.

He thought the paper exaggerated the costs of cheap storage. His investigations have led him to believe the cost of micro-reproduction to be several times that mentioned in the paper. He said that not much material is now available in microreproduction-not even I00,000 volumes. What is of concern is a million volumes. Microreproduction is a publishing venture; it must sell on a standing order in advance to get a favorable price.

He saw no overnight solution, but hoped that each year more would be available.

Eugene Powers (University Microfilms): Publishing costs can be kept down only if subscriptions are received in advance, he said. The microtext program should concentrate on (I) deteriorating publications (2) current additions. He said that he was unwilling to reproduce publications, even when there are no legal barriers, if the original publishing body objects. Such was true with the publications of the Royal Society.

Cost of good reading machines is important. Most people do not like microtext. Make their reading easier with good, machines to minimize objections.

Cost of microtext is affected by reduction ratio; it requires greater craftsmanship as ratio increases.

Stanley West (Florida): He asked whether to buy in the original or microtext. The University of Florida faculty is not opposed to microtext.

Florida has newspapers on microfilm, but what about purchasing journals against the university's future growth. He has found bibliographies unsatisfactory on film, and wonders about journals. A faculty member said that the Congressional Record on film would not be satisfactory.

Speaker for Adelphi College: He reported that Beilstein on cards has proven satisfactory.

$M r$. Babb: He noted that new reading machines would make Congressional Record easy to read.

Flora Belle Ludington (Mount Holyoke): She said that young instructors need to study locally, and a college has to face the pressure for research materials.

Early English books on microfilm was the first cooperative purchase of Mount Holyoke, Smith and Amherst. She believed that current 
material for research can be in microtext in a college, but the scholar sometimes needs to see the physical book.

She wonders what the cost is, in staff time, to help the user locate microtext and in teaching the use of the machine. Misfiling is costly; it is sometimes cheaper to replace.

Phillips Temple (Georgetown): The Chemistry Department turned down the microtext of Beilstein. Microtext prevents two using the set at once and prevents home loans.

Mr. Metcalf: He referred to the Carnegie Corporation supported study on what is unsatisfactory in microtext.

Robert F. Beach (Union Theological Seminary): He told of a cooperative project in filming a journal. To one subscriber, the cost would have been $\$ 400$; when 15 subscribed, it was reduced to $\$ 100$. $\mathrm{He}$ asked whether individual institutions should sponsor such programs or whether they should be centralized.

Charles W. David (Pennsylvania): He was prepared to discard his extensive set of the British Sessional Papers in favor of microprint but encountered strong objections.

His response to the anonymous paper was "emotional." $\mathrm{He}$ found the economic analysis "exasperating." He questioned its soundness. The paper said to him, that research librarians are a "bunch of boobs," because they have not accepted microtext as a "tidal wave."

He said it is an "invitation to librarians to destroy books by the millions."

He said you cannot give library service "without money," and you cannot "run a great library cheaply."

The paper over-simplifies the problems, he said. It is costly and laborious to discard.

Verner W. Clapp (Library of Congress): The real issue is not between microtext close at hand, and physical book at a distance. Microtext gives us publications we could not otherwise have, or it replaces deteriorating material.

\section{Correlation of Forms of Microtext for Library Use}

$\mathrm{I}^{\mathrm{s}}$

NSTEAD OF A MORE OR LESS enthusiastic advocacy of microcards, or microfilm or microprint or any other one form of microtext it would seem that there is called for at this time a study of certain of the over-all problems of microreproduction.

There exist at present two basically different forms of microtext: one transparent (i.e. microfilm), one opaque (i.e. micropaper). Each of these two forms again splits itself into two; microfilm dividing by its form, (i.e. reels or flat sheets), micropaper dividing by the method used in its production (i.e. photographically printed or photo-mechanically printed).

To make the general acceptance of microtext by libraries even more difficult each of these four basic forms is being issued (or presently proposed) in a large number of different shapes, sizes, and page arrangements. Reel microfilm is being made in four different varieties (in two different widths, and, in the case of each width, with the text photographed either at right angles to, or parallel to, the flow of the film.) No sheet microfilm is yet being commercially produced in the United States; but it is understood that two important sources are preparing to issue some soon, and that at least one will be in the standard international catalog card size, $7 \frac{1}{2} \times$ $12 \frac{1}{2} \mathrm{~cm}$. Sheet microfilm is being issued (or projected) in Europe by several publishers: in the standard catalog card size, and also in four other sizes, $7 \frac{1}{2} \times 15 \mathrm{~cm}$., $9 \times 12 \mathrm{~cm}$., $10 \frac{1}{2}$ $\times 15^{1} \mathrm{~cm}$., and $13 \times 18 \mathrm{~cm}$. In this country there is also being discussed a still larger sheet film size. There are also several attempts being made to secure for reel film the advantages of flat storage by inserting strips, or single frames, of reel film in "windows" cut into cards.

When we come to micropaper there is a similar variety of forms. The specialized form of micropaper known as microcards has, thanks to the "Code" governing their production, been so far kept standardized. Micropaper in other than microcard form is at present being produced in this country in the one size only viz. $6^{\prime \prime} \times 9^{\prime \prime}$, and in Europe in the one size only, viz. $10 \frac{1}{2} \times 15 \frac{1}{4} \mathrm{~cm}$. The American product is photomechanically printed, the European one photographically printed. Other projects are being projected, however, either here or abroad, involving at 
least two other sizes, one $5^{\prime \prime} \times 8^{\prime \prime}$, one approximately $44^{\prime \prime} \times 7^{\prime \prime}$. These various micropapers are also not standardized as to page arrangement.

To sum up: We, as librarians, are faced already with at least fourteen different, and completely uncorrelated, forms or sizes of microtext; by "uncorrelated" meaning forms that cannot be interfiled with each other, and that cannot be read except by a specially designed, or a specially adapted, reading machine of their own.

This utter lack of correlation would, one may submit, become an extremely serious matter if librarians were to accept it. But one says "if" because it is seriously to be doubted that they are going to accept it. It is very unlikely indeed that we are going to buy microtextual materials requiring storage in a dozen different kinds and sizes of containers, maintained in a dozen independent filing arrangements, and requiring for their reading a dozen entirely different types or models of reading machines. Such a burden of unstandardization would be impossible from the standpoint of both use and cost. We believe that what we as librarians want is that form of microtext-or those forms, if more than one form is absolutely necessary-which will most economically, and most effectively, solve all four of the library's great cost problems: purchase, storage, cataloging, and binding. If it should appear that any one form of microtext furnishes a complete answer to all four of these problems, then we are going to want that one form-and no other. If two or three forms of microtext appear to have a proportionate function to perform in meeting the library's problems then we are going to want those two or three forms-and no more.

Some of those best acquainted with microtext believe that it is possible to correlate all its present multiplicity of forms into one single integrated pattern eliminating all waste and duplication. And, because they believe that the above listed dozen or more forms and sizes of microtext can be brought into such a single correlated, and functionally complementative, whole, it seems to them that the encouragement of this integration is one of the most important duties at present facing us as librarians. The amount of correlation which they deem essential is such as will:

I. Make it possible to read all the various forms of microtext required for library use on one single reading machine; and

2. Make it possible to interfile all these forms in one single type of storage container and in one single filing arrangement.

This problem of standardizing microtext form and size is in no sense an unprecedented one. Seventy-five years ago Melvil Dewey faced one exactly similar. The library world at that time had in use scores of different sizes of catalog cards. In fact almost every library had a size of its own. To eliminate this intolerable hodge-podge of catalog card sizes Dewey proposed his $7 \frac{1}{2} \times 12 \frac{1}{2} \mathrm{~cm}$. "international" size. His fight against this particular chaos was not won overnight; it was a long and bitter one. It went on for years. But eventually he did win it; and his $7 \frac{1}{2} \times 12 \frac{1}{2} \mathrm{~cm}$. card is now accepted as "standard" in every country in the world. It has become far more than merely a catalog card; it is the most widely accepted, and most characteristic, library tool: the symbol of bibliographical efficiency. Billions of cards of this size are in use ; millions of dollars' worth of filing equipment has been built and bought to house them. Furthermore such profoundly practical library services as the great card distribution system of the Library of Congress would have been impossible except for this one very simple bit of standardization. No one in the library world would today dream of going back to catalog card chaos. Today, with microtext, we face exactly the same sort of chaotic variation that Dewey faced 75 years ago, and may, from a standardization of it to some one single interfileable format and size, realize the same sort of benefits. Only our benefits will be enormously greater, because the wastes resulting from a continued lack of microtextual correlation would be enormously greater.

In the solution of the first half of this problem we are fortunate, for it is optically possible to read all types of microtext on one type of reading machine. It is impossible to read micropaper with a microfilm reader. But, simply by placing microfilm against a white paper background, it is possible to read it and to read it adequately well-with any good micropaper reader. Note that the phrase here used is "adequately well." It would be absurd to claim that a micropaper reader can project a screen image of a microfilm text as bright and as clear as that which a good microfilm reader projects. It does remain true, however, that for the small library, and 
for individuals and other microtext users desirous of making one reader suffice for all types of text, a single micropaper reader can be made to do and it is further true that, provided standardization on size can be arrived at, it is possible to devise two readers-and with no necessity for more than two-that will read all sorts of microtext perfectly wellone for microfilm, and one for micropaper.

To the remark above that all existing microtexts media would seem to have a place in the integrated synthesis that we are discussing one exception will have to be made. One of the chief advocates of microtext remarked seven years ago that-for library use-microfilm in its reel form is an outmoded anachronism. $\mathrm{He}$ said that it would appear that sheet film can do all that roll film can do, and do it better. Better, because sheet microfilm possesses many of the advantages that micropaper has, namely greater compactness in storage, greater convenience in handling and use, greater opportunity for a proper catalog entry, greater interfilability, etc., etc. Europe years ago came to this conclusion, and there sheet film is al ready being widely produced. So, although microfilm, in some form, is likely to be a continuing necessity, one sees it-so far as library use is concerned-in sheet film form rather than in roll film form.

The "situations" in which-as the physician would put it-microfilm is "indicated," in fact the relative places of all forms of microtext in the over-all picture, are going to be determined, it would appear, primarily by size of edition, simply because microtext purchase cost depends primarily upon the number of copies printed of a given item; and this even though, in some cases, other factors than purchase cost may be controlling.

The primary fact is as Miles Price, of Columbia University Law Library, once put it in a dictum frequently quoted since: "Microcards are a method of publishing, microfilm a method of copying." If we add to his statement this supplementary one: photographically printed micropaper is the cheaper method of manufacture for small edition publishing; mechanically printed micropaper the cheaper method for large edition publishing; we have roughly determined the respective fields of each of these three forms.

These terms "photographically printed" and "mechanically printed" are, of course, as they are here used, not precise. Whatever form the final result may take, every sort of microtext has to start with the photographing of an original text. It is from this point that their techniques diverge. "Photographically printed" micropaper is one done on sensitized paper from a negative film. "Mechanically printed" micropaper is done on un-sensitized paper by chemical-mechanical means. Any size of micropaper can, of course, be made by either process, depending on the size of the edition, the kind and amount of illustration material to be reproduced, and to some degree on other factors.

These preliminaries leave us face to face with the one great correlational hurdle remaining, namely: the lack of uniformity which exists at present in the sizes of our various microtext media. Whether one deems this hurdle a serious one or not depends on one's viewpoint. Not a single one of the present manufacturers of microtext was ever a librarian, and some of them have little or no knowledge of the librarian's problems. As a matter of fact the sizes which these manufacturers chose for their products were often the result of sheer accident, while in other cases they were based on mathematical or commercial or typographical considerations which have little or no bibliothecal validity.

With such size origins as these it might seem that the securing of a general uniformity in microtext size for library use would not be a difficult matter to bring about. But, regardless of how these various sizes happened to originate, vested interests in them, both financial and psychological, have now been developed. And the longer these interests continue to grow the more difficult it will be for us librarians to secure that uniformity in size which it is so fundamentally essential that we have. There is, however, one basic fact very much in our favor. There exists no technological obstacle of any sort whatever to prevent a complete standardization of size for all forms of microtext. In other words the objections we face are all man-made ones, and so easily correctable ones.

Let us run over the existing size situation again, translating all the sizes into their approximate equivalents in inches, to make for easy comparison. Sheet microfilm is at present being produced (or planned) in the following sizes: $3^{\prime \prime} \times 5^{\prime \prime}, 3^{\prime \prime} \times 5^{\frac{3}{4}}, 33^{\frac{1}{2}} \times 4^{\frac{3}{4}}$, $4^{\frac{1}{2}} \times 5^{\prime \prime \prime}, 57^{\prime \prime} \times$, and in one unspecified size larger. Micropaper is at present being 
produced (or planned) in the following sizes: $3^{\prime \prime} \times 5^{\prime \prime}, 44^{\prime \prime} \times 5^{3 \prime \prime}, 4^{\frac{1}{2}}{ }^{\prime \prime} \times 7^{\prime \prime}, 5^{\prime \prime} \times 8^{\prime \prime}$, and $6^{\prime \prime} \times 9^{\prime \prime}$.

It will be noted that, of the eight sizes above listed, five are bastard sizes from a filing equipment standpoint (i.e. they fit into none of the regularly manufactured sizes of filing equipment) while three do fit into some standard equipment size. It will also be noted that, of the two overwhelmingly most common sizes of filing equipment (namely $3^{\prime \prime} \times 5^{\prime \prime}$ and $8 \frac{1}{2}$ " $\times$ I I $\left.{ }^{\prime \prime}\right)$, there exists microtext to fit only the first of the two.

Inasmuch as this statement attempts only a general presentation of the specific problem it discusses it will not present any arguments for or against any specific size. All that it argues for here is the desirability of seeking for library use some one definite standard size.

\section{Discussion}

Verner $W$. Clapp (Library of Congress): The whole matter of standardization in every matter of life is confusing. It is difficult to debate and difficult to establish an authority. The Department of Commerce and the American Standards Association work on standards for industry. Library standards have been developed within library groups; now we are in a technological area.

Microfilm standards are derived largely from the motion picture industry. Committee Z 39 of the American Standards Association (of which $\mathrm{Mr}$. Clapp is chairman), has raised questions of the problem of microtext standardization. Meanwhile, there is a strong development in Europe for standardization under the jurisdiction of the International Standards Organization; the U. S. affiliate of this organization is the American Standards Association.

The French are endeavoring to take the lead in microcopy standardization. A lot of work has been done on film strip and other microtext forms. The chairman of the Subcommittee on Photo Copies is French. Two meetings have been held, one in Paris, and a second recently, in Copenhagen. The Europeans, instead of cutting down on the number of sizes, are increasing them.

The ALA's Committee on Microcopying has not hitherto been effective; it does not seem to have had the necessary jurisdiction to get standards established. The library associations should work with the American Standards Association in order to reach agreements. Committee $Z 39$ might issue bulletins to communicate information on microtextual subjects.

Douglas Bryant (Harvard): He reported on the Copenhagen meeting. He said that Europeans are waiting to hear what we want and need. We can best communicate with them through $Z$ 39. The next meeting of the Europeans will take place in Paris in January; a $Z 39$ representative will be there. The subject will be standards for microfilm reading machines.

Mr. Clapp: The machine should follow cards; not cards the machine. For up to 50 pages, he prefers $3 \times 5$; other sizes he favors are $6 \times 9$ and $8 \frac{1}{2} \times$ II. All of these are based on existing filing equipment and the convenience which such equipment represents. The larger sizes, he believes, are best for long runs of newspapers.

$M r$. West: He questioned: Could one machine handle three sizes? He thinks librarians should encourage the development of a single machine.

Mr. Powers: A machine is being made which will take all sizes of opaque microtext. He thinks two machines, maybe three, are necessary: (I) for opaque, (2) roll film, (3) sheet film. One cannot expect a multipurpose machine to take all.

Mr. Clapp: He knows of plans for one.

$M r$. Powers: He believed it would be very expensive.

Albert C. Boni (Readex Microprint): The smaller the opaque card which has to be moved, the cheaper the machine can be. A machine for an $8 \frac{1}{2} \times$ II card would be expensive. He believed it is too early to set standards, and doubts whether one machine for both transparent or opaque is ever successful. He said firms are working on equipment to determine how best to serve readers.

Margaret Johnson (Smith): She said that a really good reader is not available yet. Patrons need to be considered, she stated. A better reader would reduce faculty resistance. She had no objection to three good readers.

$M r$. Metcalf: He had proposed 17 years ago that standardization be effected. He was 
pleased his advice had not been taken. He wonders if it is yet time for standardization. When it is time, we do not want to fail to get standards, he stated. Our talking should be about standardizing reproduction, not machines, he added.

Donald Cameron (Rutgers): The more machines Rutgers has, the more expensive they become. As improvements arise, and new machines are purchased, he has tried without success to turn his old ones in. $\mathrm{He}$ believes that the time is too early for standardization.

$M r$. Clapp: He agreed that machines are bad. He points out that the subject under discussion is standardization of materials sizes. The standardization of film, as we have it, is owed to the film industry, and because of that standardization, it is possible to order usable film from Greece, for instance.

Today's talk is not about film, but "flats," transparencies and non-transparencies. Powers can produce flat film.

We should express preferences for one or more sizes. He thinks these preferences depend upon the filming equipment we have.

$M r$. Powers: He observed that roll, card and flat each has a place. It depends upon what it is for. He thinks sheets costly. He has no reader, except an experimental one, for flat prints. He can work on rolls more cheaply.

Mr. Boni: He suggested that sizes should be expressed in inches.

Ermine Stone (Sarah Lawrence): She asked if FID had done anything for standardization.

$M r$. Clapp: He said that the International Standards Organization is the standardization agency for Europe.

Morris Gelfand (Queens): He believes that a study is required. He does not favor too specific recommendations now. He wonders if the group present is the one to speak.

Mr. Clapp: This body, having been consulted as to its preference of the 8 sizes, can transmit to the American Standards Association its opinion as an expression of preference.

Charles F. Gosnell (New York State Library): He observed that the sizes Mr. Clapp suggested are good.

$M r$. West: He believed that if we want anything done, we should tell the ASA.

Fremont Rider (Wesleyan): He agreed with the anonymous writer that we should favor standardization, but he did not believe that it is the time for regulation of sizes. $\mathrm{He}$ thought the three sizes mentioned are far enough to go.

\section{Proposed Statement on Microfilm}

\section{(Continued from page 29I)}

film material in its own collections, manuscript and rare printed materials available on film should not be reproduced by one library for another without permission of the library owning the original materials.

\section{Microfilming Clearing House}

There has been established in the Union Catalog Division of the Library of Congress a Microfilming Clearing House, the purpose of which is to provide a central source of information on extensive microfilming projects planned, in progress, or completed. Much of the material here assembled is disseminated in the Microfilming Clearing House Bulletin which is published at irregular intervals as an appendix to the Library of Congress Information Bulletin. The quality and value of this service will depend on the cooperation of all who undertake extensive microfilming projects. Therefore, to prevent unnecessary duplication of effort, all institutions are urged to report their current and completed projects on the printed cards provided by the Library of Congress and to make inquiries before starting new projects. 